\title{
Superior Performance of Ag over Pt for Hydrogen Evolution Reac- tion in Water Electrolysis under High Over-potentials
}

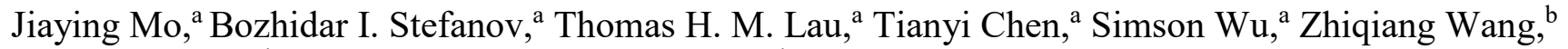 \\ Xue-Qing Gong, ${ }^{b}$ Ian Wilkinson, ${ }^{c}$ Günter Schmid, ${ }^{\mathrm{d}}$ and Shik Chi Edman Tsang ${ }^{\mathrm{a} *}$ \\ a The Wolfson Catalysis Centre, Department of Chemistry, University of Oxford, Oxford, OX1 3QR, UK \\ ${ }^{\mathrm{b}}$ East China University of Science and Technology, Shanghai, 200237, China \\ c Siemens plc, CT NTF, Wharf Road, Oxford, OX29 4BP, UK \\ d Siemens AG Erlangen-Süd, D-91052 Erlangen, Germany
}

\begin{abstract}
There has been a substantial research effort worldwide to develop non-noble metal catalysts in electrolysers for $\mathrm{H}_{2}$ production from renewable energy sources. Pt catalysts are found to display the highest hydrogen evolution reaction (HER) activity under typical experimental conditions with relatively low acidity and over-potentials. However, it is noted that catalytic activity is highly dependent on acidity and applied potential used. In real practice of a high workload electrolyser high acidity and large negative potentials are required to optimize the HER activity. We hereby report that inexpensive silver catalysts, particularly the cubic form of silver nanoparticles, can clearly exhibit superior HER activity over Pt with a different rate determining step in an electrolyser when such conditions are reached. This is attributed to the weaker Ag-H bond at the surface than Pt-H which is more favorable for $\mathrm{H}$ recombination to form $\mathrm{H}_{2}$. It is thus believed that this study provides new insights into designing economical and highly efficient catalysts that can replace the expensive noble metal analogues in a working electrolyser.
\end{abstract}

\section{INTRODUCTION}

Energy supply is one of the most significant global problems. The use of fossil fuels is not an ultimate solution due to their emission of pollutants. Extensive research is being carried out to develop a cleaner renewable energy system. ${ }^{1} \mathrm{Hy}-$ drogen energy appears to be promising among all kinds of renewable energy sources, providing a better environment and sustainability. ${ }^{2}$ High-quality hydrogen can be produced by water electrolysis based on renewable energy sources (photovoltaic, wind, tidal wave, ground heat, etc.). ${ }^{3}$ The proton exchange membrane (PEM) electrolyser is an efficient industrial method to produce large quantities of hydrogen without emitting traditional by-products associated with fossil fuels. ${ }^{4}$

In recent years, there have seen a rising interest in this idea of converting renewable energy via electrolysis into storable and transportable energy chemicals, also termed Power-toChemical such as methanol from $\mathrm{H}_{2}$ and $\mathrm{CO}_{2}$, ammonia from $\mathrm{H}_{2}$ and $\mathrm{N}_{2}{ }^{5-7}$ The significant decrease in the costs of renewable electricity and electrolyser and the possibility of carbon taxation justify the large scale production of hydrogen from water in centralised installations in the near future. Briefly, watersplitting reaction occurs at the anode, producing a large amount of $\mathrm{H}^{+}$. The $\mathrm{H}^{+}$subsequently diffuses through the proton exchange membrane (PEM) and reaches the cathode under applied potential, where it is eventually recombined and reduced into dihydrogen (Figure 1). The hydrogen evolution reaction (HER) in PEM water electrolysis is commonly catalysed by commercially available but expensive noble metals, such as Pt, and Pd. The catalyst itself has already taken up a considerable portion of the total system and capital cost, especially if there is degradation or corrosion of the carbon support. Thus, one crucial aspect of the development in HER technology is to replace the catalysts with earth abundant alternatives to produce hydrogen in a more economical way.

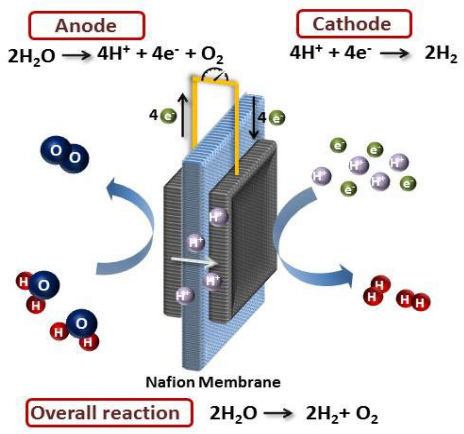

Figure 1. A schematic overview of PEM electrolyser where anode activates $\mathrm{H}_{2} \mathrm{O}$ to $\mathrm{O}_{2}$ with $\mathrm{H}^{+}$diffuses across Nafion membrane under potential to a cathodic metal catalyst for $\mathrm{H}_{2}$ production.

Although there has been large number of researches to develop non-noble metal catalysts for the HER worldwide over the past years, ${ }^{8,9}$ it is still believed that Pt-based catalysts display the highest activity. This raises the major concern whether a more active while cheaper replacement for Pt needs to be identified to justify the huge research effort. For the case of monometallic catalysts, platinum nanoparticles supported on 
carbon black (Pt/C), e.g. products commercially available from ETEK/BASF, Tanaka, and Johnson \& Matthey are generally regarded as the 'Holy-grail' catalyst for the HER. ${ }^{10,11}$ It is particularly noted that the catalytic activity of most reported HER catalysts has been commonly evaluated by cyclic or linear sweep voltammetry (CV and LSV) in weak acidified solution at low applied voltage conditions through their Tafel slope. But, the potent catalysts are rarely studied in PEM electrolyser under a high workload condition which is more relevant to the real practical conditions. Currently the main challenge in large scale industrial application of PEM electrolysis is to reduce capital and operation costs. ${ }^{12,13}$ Employing high current densities would result in a high $\mathrm{H}_{2}$ output which might justify the cost of the electrolyser. ${ }^{13}$ As far as we are aware, modern electrolyser with low internal impedance gives extremely high faradic efficiency that approaches $100 \%$. As a result, the use of higher applied potential could in principle end up in higher hydrogen production with low energy losses due to non-faradic processes such as internal contact impedance created by membrane and interfaces. Recent advance in enabling a long term durability of reactor cell of over 1000 hours has made possible at a current density of 3-6 $\mathrm{A} \mathrm{cm}^{-2}{ }^{14,15}$

Silver-based catalyst is well known for its excellent performance in electrochemical reactions. ${ }^{16}$ For example, Tang et al. ${ }^{17}$ has employed silver catalysts on polyaniline (PANi) and polypyrrole (PPy) for methanol oxidation reaction in PEMFC applications while Gonzalez-Macia et al. ${ }^{18}$ has used silverpaste electrodes in the determination of hydrogen peroxide in the glucose oxidase reaction. Particularly silver-based catalysts with different morphologies (nanocubes, nanospheres, nanowires etc.) have been widely applied in heterogeneous catalysis because of the tunable surface active sites on the various dominant facets of the metal. ${ }^{19}$ However, to the best of our knowledge, there is no literature reported on the catalytic performance of morphology-controlled silver nanoparticles as compared to typical platinum catalysts at high applied potential for PEM water electrolysis reactions.

Commercially available $20 \mathrm{wt} \% \mathrm{Pt} / \mathrm{C}$ (noble metal) from Johnson Matthey is generally found to display higher activity than Ag catalysts (Group 1B metal) under conditions of low acidic of $0.1 \mathrm{~mol} \mathrm{~L}^{-1} \mathrm{H}_{2} \mathrm{SO}_{4}$ and low current densities, such as $2 \mathrm{~mA} \mathrm{~cm}{ }^{-2}$ at $80{ }^{\circ} \mathrm{C}^{13}$ Thus, we investigated whether it gave the same catalyst order than Ag catalysts in PEM electrolyser in a range of applied potentials compared with the cyclic or linear sweep voltammetry (CV and LSV). A series of morphology-controlled silver nanoparticle catalysts (named as Ag nanocubes, $\mathrm{Ag}$ nanowires and $\mathrm{Ag}$ nanospheres) were synthesized, ${ }^{20-22}$ which was then loaded onto the Vulcan Carbon support for comparison with the $\mathrm{Pt} / \mathrm{C}$ in $\mathrm{PEM}$ cathode on acidic Nafion membrane for hydrogen evolution reaction.

Herein, we will investigate the cathode electrocatalysts at different current densities from 0 to $3.5 \mathrm{~A} \mathrm{~cm}^{-2}$ over a range of negative applied potentials. At more positive applied potentials regime $(-1.0 \sim-2.0 \mathrm{~V})$, it was found that the commercial $\mathrm{Pt} / \mathrm{C}$ catalyst in PEM electrolyser was still larger than all other metal catalysts we chose including the Ag nanoparticles. Surprisingly, when more negative potential $(-2.5 \mathrm{~V})$ was applied, the current density of the Ag catalysts increased dramatically to nearly $3.5 \mathrm{~A} \mathrm{~cm}^{-2}$, giving higher $\mathrm{H}_{2}$ productivity than the $\mathrm{Pt} / \mathrm{C}$. To understand their exceptional performance at nanoparticle scale, we probed the surface properties and correlated them with the electrocatalytic HER activity in a PEM electrolyser.

\section{EXPERIMENTAL SECTION}

Catalyst Synthesis. The $20 \mathrm{wt} \% \mathrm{Ru} / \mathrm{C}, \mathrm{Pd} / \mathrm{C}, \mathrm{Au} / \mathrm{C}$ were synthesized via wet impregnation followed by calcination reduction. ${ }^{23-25}$ The $20 \mathrm{wt} \% \mathrm{Pt} /$ graphitized carbon (Aldrich) and $20 \mathrm{wt} \% \mathrm{Ir} / \mathrm{C}$ (FuelCellStore) were commercially available. The metal species and loading of $20 \mathrm{wt} \%$ metal/carbon were confirmed by X-ray Diffraction (XRD) and Thermal Gravimetric Analysis (TGA), respectively (Figure S1 and Table S1).

The morphology-controlled silver nanoparticles (cubes, spheres and wires) were synthesized with the polyol process following the methods of Xia et al. ${ }^{20-22}$ The $20 \mathrm{wt} \%$ each form of $\mathrm{Ag}$ nanoparticle/C was then prepared by loading the asprepared morphology-controlled silver nanoparticles onto Carbon Vulcan XC72R via wet impregnation. A uniform particle distribution was confirmed by EDX (Figure S2). The morphology of each silver nanoparticle was also checked by UV-visible absorption spectrum (Figure S3).

Electrolyser Fabrication and Testing. Membrane electrode assemblies were fabricated with Nafion 211 membrane sandwiched in between the two catalyst electrodes. The Nafion 211 membranes purchased from FuelCellStore were cut into $2.5 \mathrm{x}$ $2.5 \mathrm{~cm}^{2}$ pieces. These acidic membranes were pretreated by soaking in $3 \% \mathrm{H}_{2} \mathrm{O}_{2}$ at $80{ }^{\circ} \mathrm{C}$ for an hour to remove organic impurities, further soaking in $0.5 \mathrm{M} \mathrm{H}_{2} \mathrm{SO}_{4}$ at $80{ }^{\circ} \mathrm{C}$ for an hour to ion exchange the membrane completely and finally soaking in Millipore water at $80{ }^{\circ} \mathrm{C}$ for an hour. After that, the $20 \mathrm{wt} \%$ metal on Vulcan carbon or $20 \mathrm{wt} \% \mathrm{Pt} / \mathrm{C}$ reference and Nafion ionomer ( $5 \mathrm{wt} \%$ solution, Aldrich) were mixed in a $3: 1$ weight ratio. Separately, the $\mathrm{IrO}_{2}$ catalyst (Aldrich) and Nafion ionomer ( $5 \mathrm{wt} \%$ solution, Aldrich) were also mixed in a 3:1 weight ratio. The $20 \mathrm{wt} \%$ metal $/ \mathrm{C}$ and $\mathrm{IrO}_{2}$ catalyst/ionomer mixtures were both dispersed in 3:1 volume ratio mixture of isopropanol and DI water. The catalyst/ionomer solutions were sonicated for $1 \mathrm{~h}$ and then deposited on the opposite sides of the Nafion membrane by spray casting. The $20 \mathrm{wt} \%$ metal $/ \mathrm{C}$ was loaded on the cathode side at $0.4 \pm 0.05 \mathrm{mg} \mathrm{cm}^{-2}$ of the pure metal and $\mathrm{IrO}_{2}$ catalysts was loaded on the anode side at $2.5 \pm 0.2 \mathrm{mg} \mathrm{cm}^{-2}$ over a $1.5 \times 1.5 \mathrm{~cm}^{2}$ active area. The catalyst-loaded Nafion membrane was hot-pressed between carbon paper (Sigracet GDL 29BC) at the cathode side and Ti mesh (FuelCell Store) and at the anode at $135^{\circ} \mathrm{C}$. The electrolyser performance was evaluated at $80{ }^{\circ} \mathrm{C}$ and under ambient pressure for all measurements. Deionized water was fed into the anode side at a flow rate of $4 \mathrm{~mL} / \mathrm{min}$. The polarization curves were recorded by a TENMA programmable potentiostat. The rate of hydrogen produced can be derived through the measurement of current density. 
a)

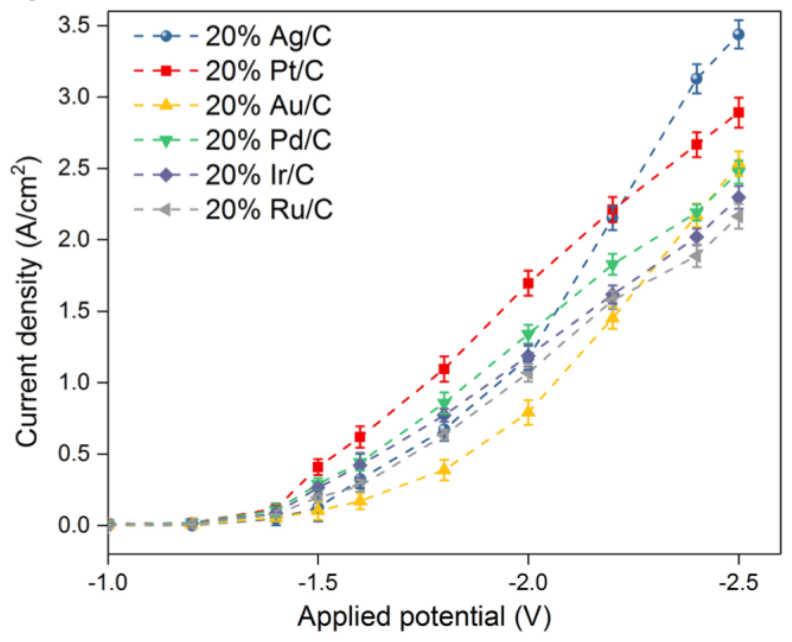

b)

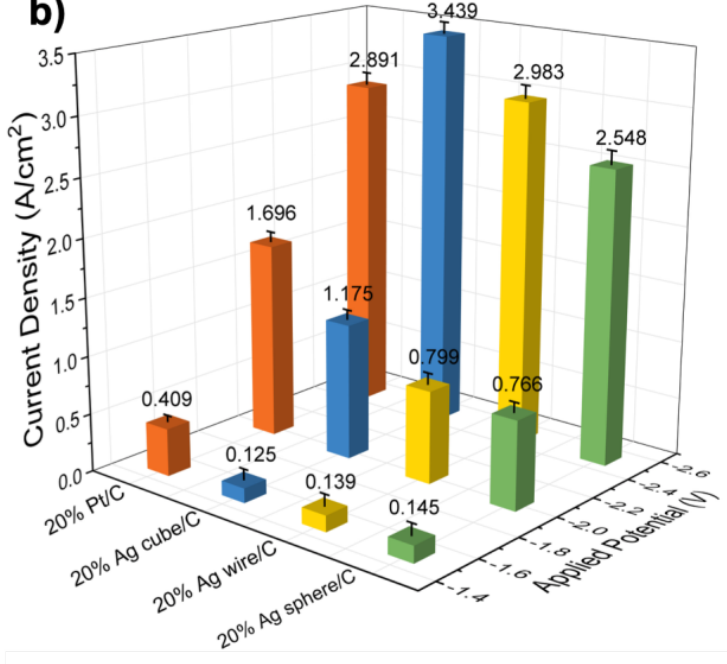

Figure 2. Electrocatalytic measurements of $20 \%$ metal/C catalysts in PEM electrolyser. a) Current-Voltage polarization curves of electrolyser with different catalysts at $\mathrm{T}=80{ }^{\circ} \mathrm{C}$. b) Comparison of three morphology-controlled $\mathrm{Ag}$ catalysts with commercial $\mathrm{Pt} / \mathrm{C}$ catalyst. $20 \%$ $\mathrm{Pt} / \mathrm{C}$ (orange line), 20\% Ag nanocubes/C (blue line), 20\% Ag nanowires/C (yellow line), 20\% Ag nanospheres/C (green line) are cathode catalysts and the anode catalyst is $\mathrm{IrO}_{2}$ for all MEAs at $80{ }^{\circ} \mathrm{C}$; Cathode: $0.4 \pm 0.05 \mathrm{mg} \mathrm{cm}{ }^{-2}$ of the pure metal; Anode: $2.5 \pm 0.2 \mathrm{mg} \mathrm{cm}^{-2}$ of $\mathrm{IrO}_{2}$ catalysts. Error bars represent the error in using separate electrodes.

In principle, a reference electrode with high impedance can be added to check whether such a two-electrode electrolyser assembly is polarized. ${ }^{26}$ However, we were unable to do this for our electrolyser due to the design characteristics. As a result, we can only give the overall potential difference between the two electrodes without quoting the absolute potentials for each electrode. Interestingly, for a comparable electrolyser, Brightman and co-workers measured the polarization for both electrodes by constructing a NPL reference electrode with an added salt bridge. According to their results, there were only marginal polarizations in the two electrodes even when 1.5-2.0 V was used. ${ }^{26}$ Cell performance was found to be unaffected by the presence of the reference electrode in their configuration and no correction was required for ohmic potential drop. While we acknowledge that there might have a degree of polarization in our electrodes as we were using a higher current density, a significantly higher over-potential is required at the anode than at cathode due to the more facile kinetics of hydrogen evolution. Nevertheless, $\mathrm{IrO}_{2}$ was fixed as an anode catalyst for OER throughout all the experiments. It is therefore believed that the comparative results of different cathodic catalysts as shown later will not be affected. Due to the internal resistance of the cell, a current efficiency of 80$85 \%$ was reached instead of $100 \%$ as shown from our GC analysis for the hydrogen production.

Thermal Gravimetric Analysis (TGA). Thermal gravimetric analysis was carried out using an SDT-TGA Q600 at a heating rate of $10{ }^{\circ} \mathrm{C} / \mathrm{min}$ from $40^{\circ} \mathrm{C}$ to $900{ }^{\circ} \mathrm{C}$.

Transmission Electron Microscopy (TEM). Highresolution transmission electron microscopy was carried out using a STEM (JEOL JEM-2100F) operated at $200 \mathrm{kV}$.

Scanning Electron Microscopy (SEM). The SEM was performed using a Field Emission Scanning Electron Microscope (Tescan MAIA3) operated at $10 \mathrm{kV}$.

Linear Sweep Voltammetry (LSV). A three-electrode system controlled by $\mu$-AUTOLAB III potentiostat (Eco-Chemie,
Netherlands) was applied to carry out all the measurements. A platinum coil counter electrode and an $\mathrm{Ag} \mid \mathrm{AgCl}\left(1 \mathrm{~mol} \mathrm{~L}^{-1}\right.$ $\mathrm{KCl})$ reference electrode were used in this study. To prepare the working electrode, $4 \mathrm{mg}$ of the electrocatalyst and $80 \mu \mathrm{L}$ of $5 \mathrm{wt} \%$ Nafion ${ }^{\circledR} 117$ solution will be dispersed in $1 \mathrm{~mL}$ of water/ethanol $(4: 1 \mathrm{v} / \mathrm{v})$ and then followed by $30 \mathrm{~min}$ sonication to create a homogeneous ink. The ink was then dropcoated onto the surface of a glassy carbon electrode with a surface diameter of $3 \mathrm{~mm}$. All measurements were calibrated with respect to the reversible hydrogen electrode (RHE).

Density Functional Theory (DFT). All DFT calculations were performed using Vienna Ab-initio Simulation Package (VASP). ${ }^{27}$ The exchange-correlation energy and potential were described by the generalized gradient approximation (GGAPW91). ${ }^{28,29}$ The kinetic energy cut-off for the wave function expanded in the plane-wave basis was set as $400 \mathrm{eV}$. To optimize the structures, the calculation was performed until the maximum force upon each relaxed atom was less than 0.05 $\mathrm{eV} / \AA$. The vacuum height was set as $15 \AA$ to eliminate the interaction between neighboring slabs.

The adsorption energy $\left(E_{a d s}\right)$ was calculated as follows:

$E_{\text {ads }}=E_{\text {total }}-E_{\text {substrate }}-E_{\text {gas-phase adsorbate }}$

where $E_{\text {total }}$ is the calculated total energy of the adsorption system, $E_{\text {substrate }}$ is the energy of the clean substrate and $E_{\text {gas- }}$ phase adsorbate is the energy of the gas-phase molecule.

\section{RESULTS AND DISCUSSION}

Catalytic Activities. The electrocatalytic HER performance of the $20 \mathrm{wt} \% \mathrm{metal} / \mathrm{C}$ was explored using a PEM electrolyser. At the outset of this study, six different $20 \mathrm{wt} \%$ metals (Ru, $\mathrm{Pd}$, Ir, Au, Ag and Pt) loaded onto the carbon each were used as the cathode catalyst in the PEM electrolyser. Figure $2 \mathrm{a}$ depicts the HER polarization curves of the different metal containing cathode catalysts (error estimations were based on at least three repeatable measurements). Clearly, at more positive 
applied potentials $(-1.0 \sim-2.0 \mathrm{~V})$, it is found that the current density of $20 \mathrm{wt} \% \mathrm{Pt} / \mathrm{C}$, the commercial catalyst for PEM electrolysis, is indeed larger than all other metal catalysts including the Ag nanoparticles. Surprisingly, when more negative potential $(-2.5 \mathrm{~V})$ or higher over-potential is applied, the current density of the Ag catalysts increases dramatically to nearly $3.5 \mathrm{~A} \mathrm{~cm}^{-2}$, giving higher $\mathrm{H}_{2}$ productivity. Compared to the commercial $20 \mathrm{wt} \% \mathrm{Pt} / \mathrm{C}$ reference, the HER performance was improved by $20 \%$ in the case of Ag nanoparticles. In order to gain understanding of the tremendous improvement in HER activity, surface specific properties of the silver nanoparticles were determined. Different morphologies of the Ag nanoparticles (cubes, wires and spheres) were then synthesized for comparison. Among the morphology-controlled silver nanoparticles, $20 \mathrm{wt} \% \mathrm{Ag}$ nanocubes/C shows consistently higher current density compared with the commercial $20 \mathrm{wt} \% \mathrm{Pt} / \mathrm{C}$ which is comparable to $20 \mathrm{wt} \% \mathrm{Ag}$ nanowires/C with the same metal loading of $0.4 \pm 0.05 \mathrm{mg} \mathrm{cm}^{-2}$ for the three catalysts at the more negative potential of $-2.5 \mathrm{~V}$ (Figure 2b, Figure S4). As a result, the applied potential of $-2.5 \mathrm{~V}$ was placed on hold to the $20 \mathrm{wt} \% \mathrm{Ag}$ nanocubes/C, no deactivation was observed within the experimental testing time (Figure S5). As far as we are aware, the high rate of hydrogen production over Ag catalyst on cathode is not reported. The results clearly demonstrate that simple but inexpensive Ag catalysts can outperform the
'Holy-grail' Pt catalyst in PEM electrolyser under high workload conditions without noticeable deactivation.

Structural Characterizations and Morphological Stability. To uncover the macroscopic and microscopic properties controlling the observed HER activities, a range of different characterization techniques were applied to study the morphology of silver nanoparticles (spheres, wires and cubes).

In Figure 3a, it shows the diffractograms of Ag nanowires, $\mathrm{Ag}$ nanospheres, and $\mathrm{Ag}$ nanocubes. Lattice indexing indicates that all these $\mathrm{Ag}$ structures are in face-center cubic phase. Analysis of $\mathrm{Ag}$ nanoparticles on flat substrate confirms that the as-prepared $\mathrm{Ag}$ nanospheres, nanowires and nanocubes, are highly crystalline silver (JCPDF 87-0597). For single crystalline $\mathrm{Ag}$ nanocubes, a significant change in the relative intensity of (111) and (200) peaks in the XRD patterns corresponds to a change in morphology. The intense (200) peak (higher ratio of (200) peak to (111) peak) can be ascribed to the texturing effect of the ordered nanocubes on the flat substrate. With the preferential orientation $<200>$ perpendicular to the substrate, it indicates that most cubes are aligned on the substrate with $\{100\}$ being oriented upward, which corresponds to the observed TEM shown below. ${ }^{30}$

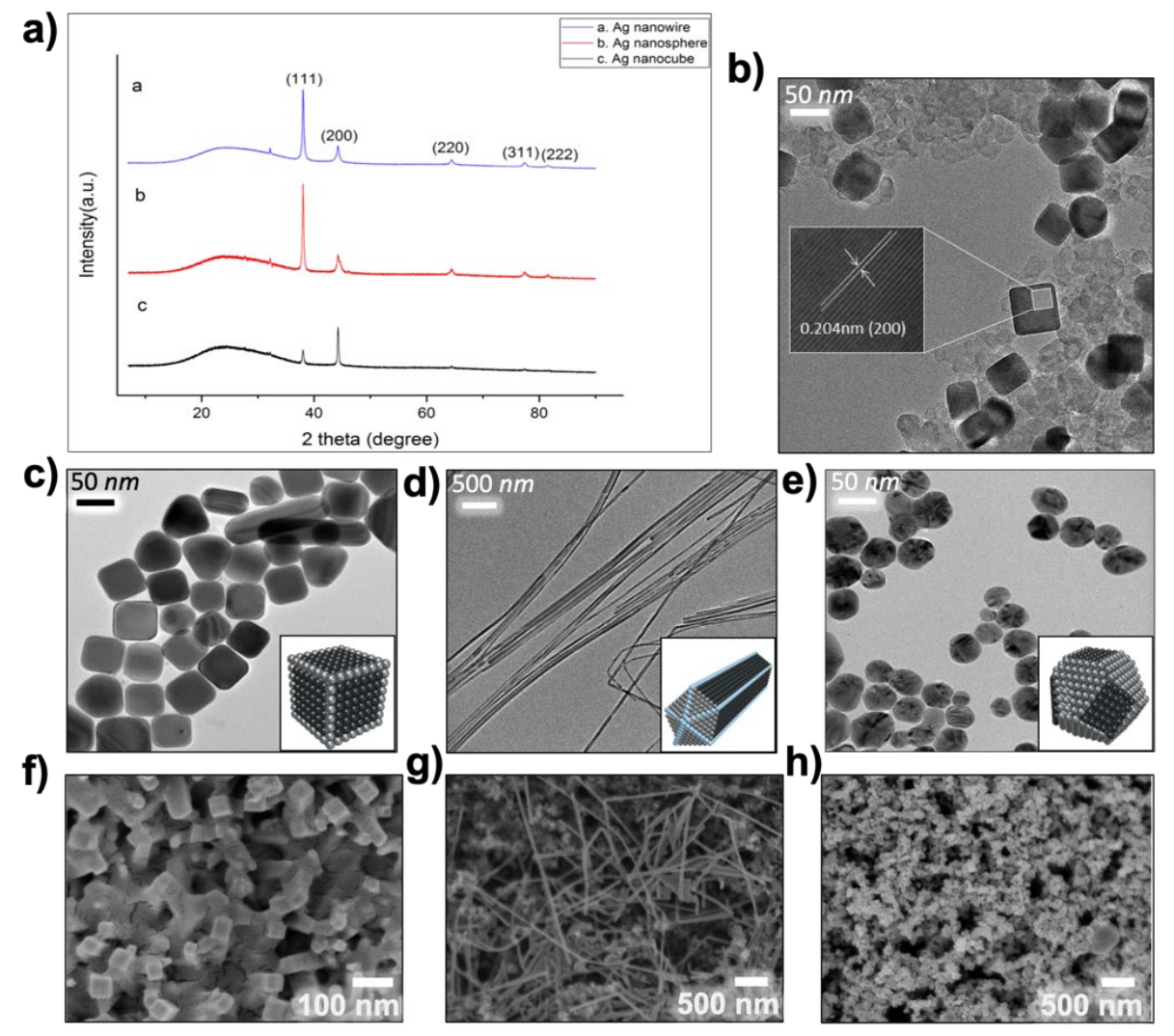

Figure 3. XRD diffractograms, TEM and SEM images of the morphology-controlled Ag nanoparticles. a) XRD profile of silver nanoparticle samples of Ag nanowires, Ag nanospheres, and Ag nanocubes produced for catalysis. b) TEM and HRTEM of 20 wt $\%$ Ag cubes on carbon with lattice parameter of $0.204 \mathrm{~nm}$ (see Figure S8). c-e) TEM images of Ag cubes, Ag wires and Ag spheres with schematic illustrations, respectively. In the images, light grey: $\{111\}$ facets, black: $\{100\}$ facets, blue: $\{111\}$ twin planes. f-h) SEM images of the postreaction $20 \mathrm{wt} \% \mathrm{Ag}$ cubes/C, $20 \mathrm{wt} \% \mathrm{Ag}$ wires/C and $20 \mathrm{wt} \% \mathrm{Ag}$ spheres/C on carbon paper after HER testing at an applied potential of $2.5 \mathrm{~V}$. 
Figure 3c-e displays the TEM images and the corresponding size distribution (Figure S6) of the faceted Ag nanoparticles. The average edge length of the nanocubes is shown to be $45 \pm$ $3 \mathrm{~nm}$ whereas the average diameter of the Ag nanowires is 45 $\pm 2 \mathrm{~nm}$. As for the polycrystalline Ag nanospheres, the average size is $43 \pm 2 \mathrm{~nm}$. The high-resolution TEM image (Figure $3 \mathrm{~b}$ ) shows the $\mathrm{d}$-spacing value is $2.0 \AA$ on termination of $\mathrm{Ag}$ nanocubes, which can be assigned to the d-spacing of $\{200\}$ facets for the face-centered-cubic (FCC) Ag. ${ }^{31}$ The $<200>$ axes indicates that the Ag nanocubes' surfaces are bounded by $\{100\}$ facets (Figure S7). ${ }^{32}$ In contrast, the conventional polycrystalline Ag nanospheres are terminated with higher index planes and a more thermodynamically favorable $\mathrm{Ag}(111){ }^{32}$

Ag nanowires have a pentagonal cross section, and they are composed of five single-crystalline domains separated by $\{111\}$ twin planes and each nanowire has five equivalent flat side surfaces. To shed light on the formation of $\mathrm{Ag}$ nanowires, it has been proposed that they grew from decahedral seed present in the early stage of the reaction. ${ }^{33}$ The actual morphology of the seed should be similar in shape to a Mark's decahedron, which can be obtained by elongating the classic decahedron in the $\langle 110\rangle$ directions and replacing the edges at the twin boundaries with re-entrant surfaces composed of $\{111\}$ facets. This modification both lowers the energy of the decahedron and produces $\{100\}$ planes on its sides. ${ }^{34}$ The Ag nanowires are then formed with $\{100\}$ side facets and $\{111\}$ facets ends. As the schematic illustration shown above, the Ag nanocubes are dominated by the $\{100\}$ facets and Ag nanowires with both $\{100\}$ and $\{111\}$ facets and the Ag nanospheres is majority terminated with the high index facets. With the morphology-controlled Ag nanoparticles, it allows us to study the HER on different exposed Ag surface. ${ }^{35}$

After the testing of the three morphology-controlled $20 \mathrm{wt} \%$ silver nanoparticles/C, they were also checked by TEM and SEM. As seen from Figure $3 f-h$, post-testing samples were imaged by removing the carbon paper from MEA after HER catalytic testing at an applied potential of $-2.5 \mathrm{~V}$. Also, the post-testing catalysts were collected by scrapping the catalyst

a)

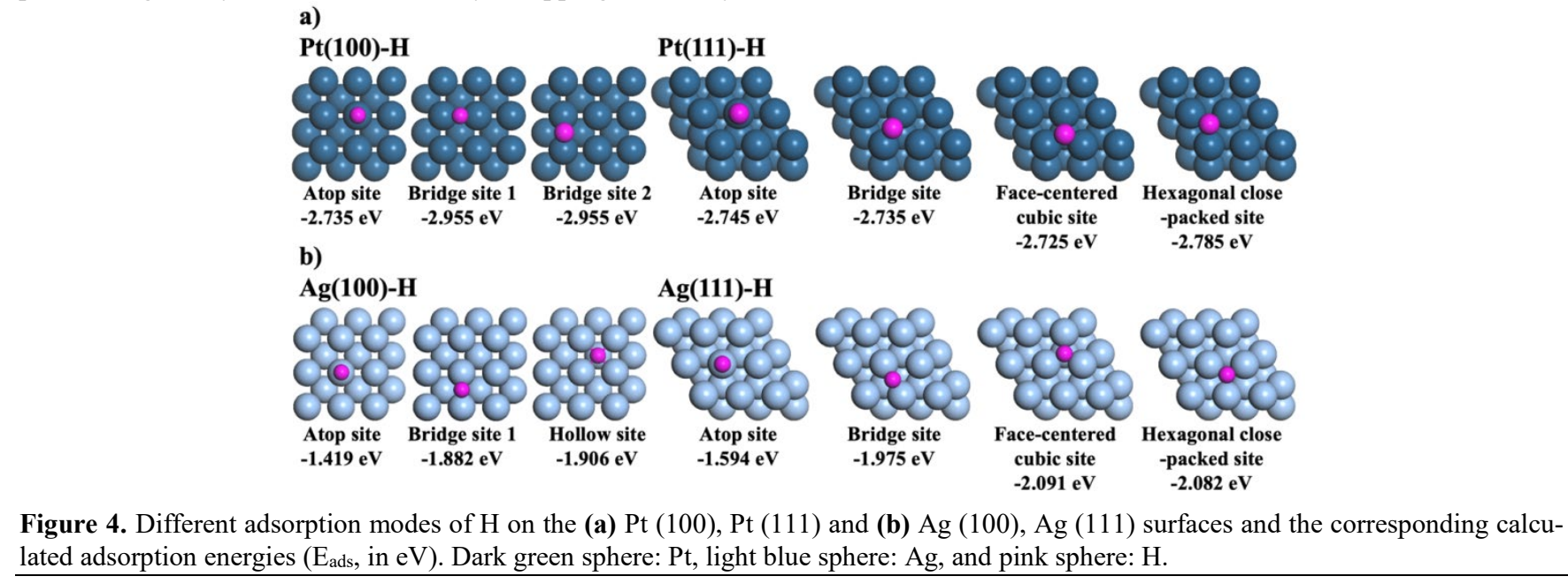

Figure 4. Different adsorption modes of $\mathrm{H}$ on the (a) Pt (100), Pt (111) and (b) $\mathrm{Ag}(100), \mathrm{Ag}$ (111) surfaces and the corresponding calculated adsorption energies ( $E_{a d s}$, in $\left.\mathrm{eV}\right)$. Dark green sphere: Pt, light blue sphere: Ag, and pink sphere: $\mathrm{H}$. powder from the carbon paper then dispersed in isopropanol for TEM (Figure S9). Both techniques indicate the shape and average particle size remained the same. The SEM images at wider views showed clearly the maintenance of size and morphology of these Ag nanoparticles after the exposure of large negative potential for the HER reaction in PEM electrolyser.

Structure-Activity Correlations and Electrocatalytic Performance. It is evident from the testing that the $20 \mathrm{wt} \% \mathrm{Ag}$ nanocubes/C and $\mathrm{Ag}$ nanowires/C give better catalytic performance on HER than that of the commercial $20 \mathrm{wt} \% \mathrm{Pt} / \mathrm{C}$ at the applied potential of $-2.5 \mathrm{~V}$ but the order is reversed at more positive applied potentials. In order to rationalize these electrochemical HER performances of morphology-controlled $\mathrm{Ag}$ nanoparticles catalysts as compared to $\mathrm{Pt} / \mathrm{C}$ which may lead to the development of improved PEM electrolyser, the fundamental steps for dihydrogen formation from proton reduction should be considered.

A typical HER reaction under an acidic medium comprises two possible elementary reaction routes, Volmer-Heyrovsky and Volmer-Tafel (Figure S10). If the rate determining step (RDS) involves $\mathrm{M}-\mathrm{H}$ bond formation as described in both the mechanisms, we encode it as 'Volmer' limiting. Conversely, RDS involves $\mathrm{M}-\mathrm{H}$ bond breaking on metal surface to form surface dihydrogen where hydrogen gas is then evolved at the cathode. It is described as 'Tafel' limiting. The rate determining step indicated by Tafel slope can be used, which is associated with the binding energy between the metal catalyst surface and hydrogen atoms as previously reported in a typical 'volcano' response. ${ }^{35,36} \mathrm{Pt}$ is generally believed to give the optimal M-H bond strength in the volcano at onset potential with constant acidity and coverage hence giving the highest rate in a catalytic cycle. In fact, in the literature, various Tafel slopes dependent on reaction conditions have been reported. The $20 \mathrm{wt} \% \mathrm{Pt} / \mathrm{C}$ catalyst exhibits a Tafel slope of $30 \mathrm{mV} / \mathrm{dec}$ in $0.5 \mathrm{M} \mathrm{H}_{2} \mathrm{SO}_{4}$ in $\mathrm{CV} / \mathrm{LSV}$ at lower overpotential range, 120 $\mathrm{mV} / \mathrm{dec}$ under PEM conditions with a wider overpotential range and $125 \mathrm{mV} / \mathrm{dec}$ in $0.5 \mathrm{M} \mathrm{NaOH}$ solution. ${ }^{37,38}$ Detailed 


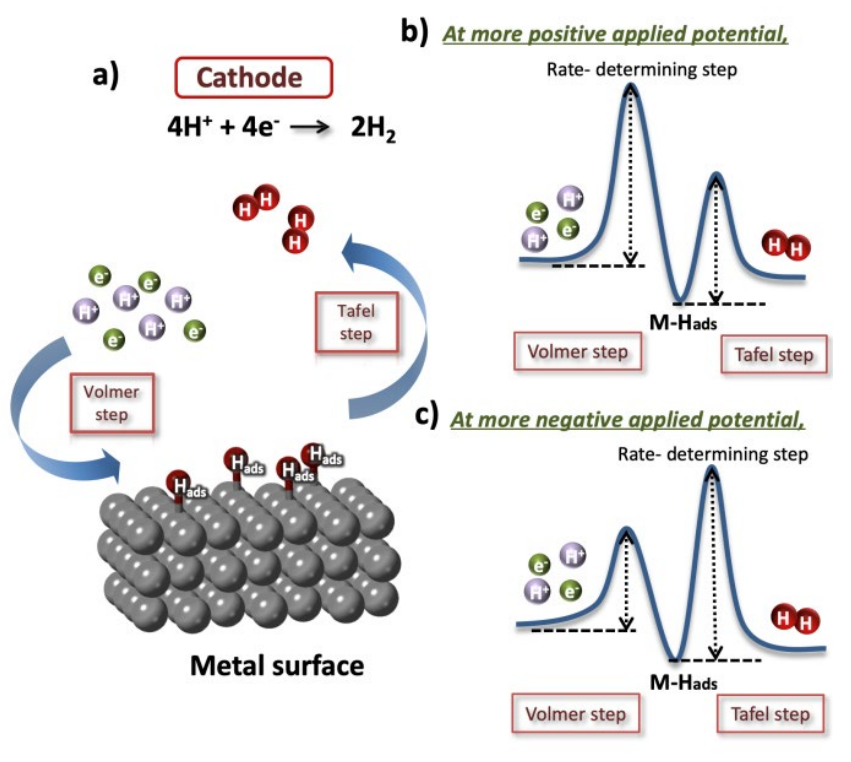

Figure 5. Two possible rate determining steps. a) A schematic overview of hydrogen evolution reaction pathway at the cathode side. b) Higher Volmer barrier as the rate determing step at more positive applied potential. c) Higher Tafel barrier as the ratedeterming step at more negative applied potential for HER on cathodic catalyst under acidic conditions.

microkinetic analysis shows that the electrocatalytic activity is strongly dependent on applied $\mathrm{pH}$ and potential which in turn on surface species coverage. ${ }^{38}$

To gain further understanding on the reaction mechanism, the adsorptions of hydrogen at platinum and silver surfaces were studied by Density Functional Theory (DFT) calculations. Different adsorption sites of $\mathrm{H}$ at Pt (100), Pt (111), Ag (100) and Ag (111) were considered and the calculated results are presented in Figures $4 \mathrm{a}$ and $4 \mathrm{~b}$ as well as Table 1. From these results, one can clearly see that, at the corresponding sites, $\mathrm{H}$ is adsorbed more strongly on $\mathrm{Pt}$ than $\mathrm{Ag}$ for both (100) and (111) facets. A schematic overview of hydrogen evolution reaction pathway at the cathode side, which is involving Volmer and Tafel RDS, is shown in Figure 5a. Clearly, at more positive applied potential in PEM conditions, the $\mathrm{H}^{+}$flux through the membrane and external current density are of limited availability, which makes the Volmer reaction (M-H bond formation) rate limiting (Figure $5 \mathrm{~b}$ ). It gives the Pt surface at low coverage of $\mathrm{H}$ atoms with the strongest $\mathrm{M}-\mathrm{H}$ bond the highest activity. ${ }^{37,38}$ It is also well-known that the hydrogen adsorption energy depends on the facet of the active metal. ${ }^{39}$ As reflected by our XRD and TEM above, Ag cubes are confirmed to cover mainly with (100) facets, short Ag wires with (100) side and (111) faceted ends and polycrystalline Ag spheres with higher index surfaces. The adsorption energy indicates that $\mathrm{H}$ is adsorbed more strongly on close packed $\mathrm{Ag}$ (111) when compared to the loose-packed Ag (100) in the same absorption sites. Since the rate determining step (RDS) is the adsorption of proton (and electron) onto the metal catalyst surface at more positive applied potentials, the stronger $\mathrm{M}-\mathrm{H}$ bond of $\mathrm{Ag}$ spheres (shown in Table 1) with higher index planes among the three Ag samples shows higher hydrogen evolution rate. Thus, the adsorption strength order agrees with the experimental trend in activity as $\mathrm{Pt}>\mathrm{Ag}$ spheres $>\mathrm{Ag}$ wires $>\mathrm{Ag}$ cubes at $-1.5 \mathrm{~V}$ (see Figure $2 \mathrm{~b}$ ).

However, at more negative applied potential $(-2.5 \mathrm{~V})$ in local polarized acidic environment in PEM conditions, the metal catalyst surface is readily covered with adsorbed hydrogen at a significant quantity, which eventually leads to a change of the rate determining step to $\mathrm{M}-\mathrm{H}$ bond breaking (Figure $5 \mathrm{c}$ ). The reaction pathway is associated with the $\mathrm{H}$ recombination from $\mathrm{M}-\mathrm{H}$ in Tafel step, the weaker M-H bond of Ag (100) cubes this time allows surface migration and facilitates $\mathrm{H}_{2}$ formation. As a result, the trend in activity as $\mathrm{Ag}$ spheres $<\mathrm{Pt} \sim \mathrm{Ag}$ wires $<$ Ag cubes is established at an applied potential of $-2.5 \mathrm{~V}$. The order of the three morphology-controlled Ag nanoparticles is totally reverse of that at more positive potentials, as shown from our experiments (Figure 2b).

Table 1. Calculated $\mathrm{H}$ adsorption energies at different sites of Pt (100), Pt (111), Ag (100) and Ag (111). For (100) facets, ads 1 is atop site, ads 2 is bridge site and ads 3 is hollow site for $\mathrm{Ag}$ and bridge site for Pt; while for (111) facets, ads 1 is atop site, ads 2 is bridge site, ads 3 is face-centered cubic site and ads 4 is hexagonal close-packed site (see Figure 4).

\begin{tabular}{ccccc}
\hline & $\mathbf{E}_{\text {ads1 }} / \mathbf{e V}$ & $\mathbf{E}_{\text {ads2 }} / \mathbf{e V}$ & $\mathbf{E}_{\text {ads3 }} / \mathbf{e V}$ & $\mathbf{E}_{\text {ads4 }} / \mathbf{e V}$ \\
\hline $\operatorname{Pt}(\mathbf{1 0 0})$ & -2.735 & -2.955 & -2.955 & $/$ \\
\hline $\mathbf{P t}(\mathbf{1 1 1})$ & -2.745 & -2.735 & -2.725 & -2.785 \\
\hline $\mathbf{A g}(\mathbf{1 0 0 )}$ & -1.419 & -1.882 & -1.906 & $/$ \\
\hline $\mathbf{A g}(\mathbf{1 1 1})$ & -1.594 & -1.975 & -2.091 & -2.082 \\
\hline
\end{tabular}



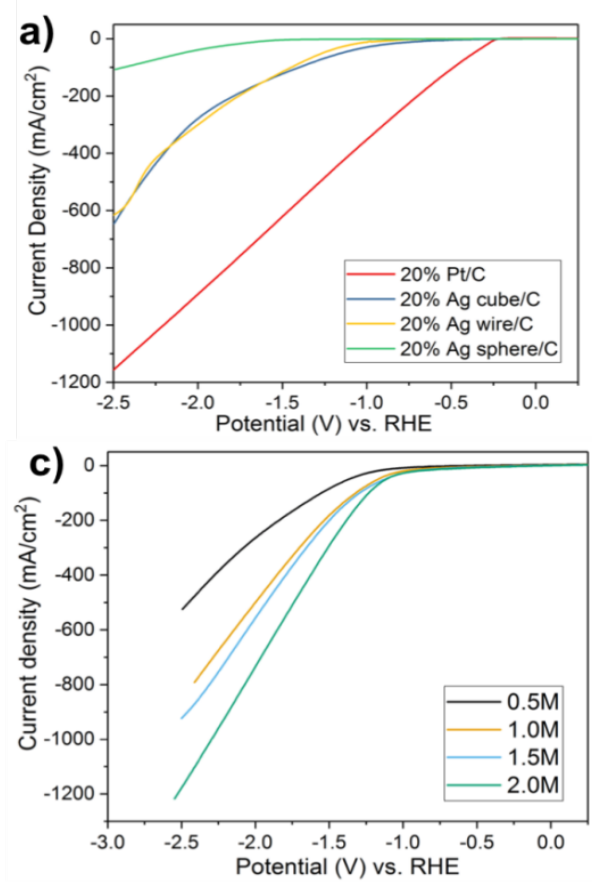
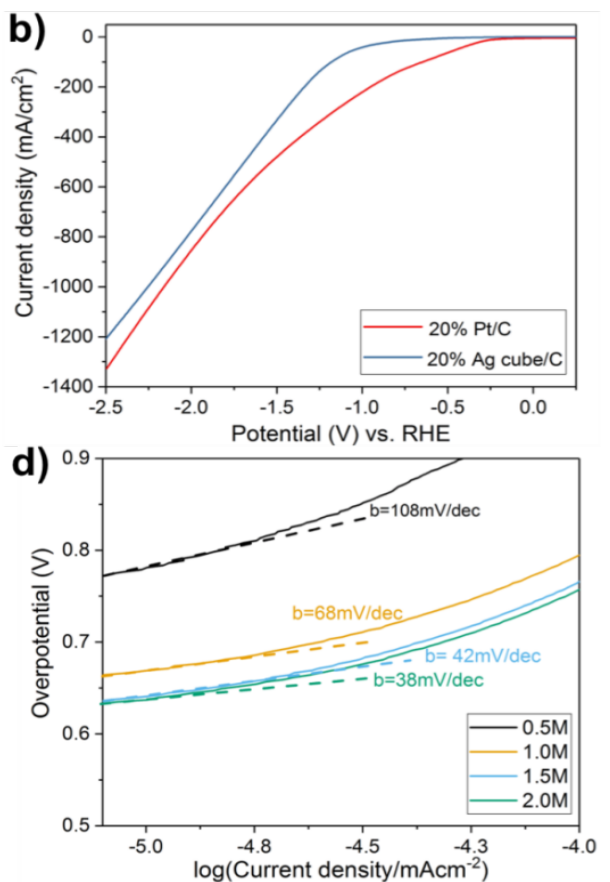

Figure 6. HER activity analysis by linear sweep voltammography, LSV. a) LSV of the $20 \mathrm{wt} \% \mathrm{Ag}$ cubes/C, wires/C, spheres/C and 20 wt $\% \mathrm{Pt} / \mathrm{C}$ reference in $\mathrm{N}_{2}$-purged $0.5 \mathrm{M} \mathrm{H}_{2} \mathrm{SO}_{4}$ solution; b) LSV of $20 \mathrm{wt} \% \mathrm{Ag}$ cubes/C and $20 \mathrm{wt} \% \mathrm{Pt} / \mathrm{C}$ reference in $\mathrm{N}_{2}$-purged $2.0 \mathrm{M}$ $\mathrm{H}_{2} \mathrm{SO}_{4}$ solution; c) LSV of $20 \mathrm{wt} \% \mathrm{Ag}$ cubes/C in $\mathrm{N}_{2}$-purged $0.5 \mathrm{M} \mathrm{H}_{2} \mathrm{SO}_{4}, 1.0 \mathrm{M} \mathrm{H}_{2} \mathrm{SO}_{4}, 1.5 \mathrm{M} \mathrm{H}_{2} \mathrm{SO}_{4}, 2.0 \mathrm{M} \mathrm{H}_{2} \mathrm{SO}_{4}$ solution. d) Corresponding Tafel plots recorded on glassy carbon electrodes with $20 \mathrm{wt} \% \mathrm{Ag}$ cubes/C catalysts in $\mathrm{N}_{2}$-purged $0.5 \mathrm{M} \mathrm{H}_{2} \mathrm{SO}_{4}, 1.0 \mathrm{M} \mathrm{H}_{2} \mathrm{SO}_{4}, 1.5$ $\mathrm{M} \mathrm{H}_{2} \mathrm{SO}_{4}, 2.0 \mathrm{M} \mathrm{H}_{2} \mathrm{SO}_{4}$ solution. All the LSV are measured from $0.25 \mathrm{~V}$ to $-2.5 \mathrm{~V}$ at a scan rate of $50 \mathrm{mV} \mathrm{s}^{-1}$. A slower scan rate $\left(5 \mathrm{mV} \mathrm{s}^{-1}\right)$ is used for the LSV in Figure S11.

The Surface Electrochemistry of Morphology-controlled 20 wt\% Ag nanoparticles/C Catalysts. To get insight to the surface electrochemical redox process, linear sweep voltammetry (LSV) was measured with a three-electrode system after the HER polarization curves. The potential was raised from $0.25 \mathrm{~V}$ to $-2.5 \mathrm{~V} / \mathrm{RHE}$ in $\mathrm{N}_{2}$-purged $0.5 \mathrm{M} \mathrm{H}_{2} \mathrm{SO}_{4}$ to monitor the activity of all four catalysts. As seen from Figure $6 a-b$, the onset potential for proton reduction observed for $20 \mathrm{wt} \% \mathrm{Pt} / \mathrm{C}$ reference is much more positive than that of silver catalysts, depicting higher activity. At relatively more positive potentials $(>-1.5 \mathrm{~V})$, higher rates of hydrogen evolution (current densities) are observed over the $\mathrm{Pt} / \mathrm{C}$ than the various forms of $\mathrm{Ag}$ catalysts under low acidity condition $\left(0.5 \mathrm{M} \mathrm{H}_{2} \mathrm{SO}_{4}\right)$. At more negative potentials, the same trend is seen as well.

This is somewhat contradictory to the activity rank measured at more negative potential using the PEM as mentioned. The discrepancy can be ascribed to the poor proton availability for the catalyst in $0.5 \mathrm{M} \mathrm{H}_{2} \mathrm{SO}_{4}$ with an appalling proton diffusion rate when compared to the fully acidified Nafion membrane $\left(\sim 0.1 \mathrm{~S} \mathrm{~cm}^{-1}\right) .{ }^{40}$ Therefore a stronger acidic electrolyte was used to mimic the PEM cathodic conditions. When using 2.0 $\mathrm{M} \mathrm{H}_{2} \mathrm{SO}_{4}$, it is interesting to find from the Figure $6 \mathrm{~b}$ that the current density becomes comparable between $20 \mathrm{wt} \% \mathrm{Ag}$ nanocubes $/ \mathrm{C}$ and $20 \mathrm{wt} \% \mathrm{Pt} / \mathrm{C}$ reference at $-2.5 \mathrm{~V}$. This is due to the fact that more protons are available for HER on the morphology-controlled Ag catalysts. Under more negative applied voltage with higher surface coverage of $\mathrm{H}$, the weaker Ag-H surface bond becomes more favorable for $\mathrm{H}$ recombination to sustain higher HER activity (Tafel limiting step). Increasing the electrolyte acidity of LSV corresponds to the in- crease in proton flux: the current density increases at more negative applied potential. From the Figure $6 \mathrm{c}-\mathrm{d}$, it is also interesting to reveal that the slopes of the Tafel plots progressively become gentler with increasing electrolyte acidity. At $0.5 \mathrm{M} \mathrm{H}_{2} \mathrm{SO}_{4}$, Tafel slope of $108 \mathrm{mV} / \mathrm{dec}$ is obtained whereas at $2.0 \mathrm{M} \mathrm{H}_{2} \mathrm{SO}_{4}$ the slope of $38 \mathrm{mV} / \mathrm{dec}$ can be deduced. These observations seem to agree with the analysis of Conway and Tilak who stated that the lower surface coverage of $\mathrm{H}$ at lower over-potential gives Volmer limited process but higher $\mathrm{H}$ coverage at higher overpotential is characterized with Tafel limited process. ${ }^{41}$ Thus, this result clearly indicates that the proton availability and surface coverage must be one of the effective factors for HER with morphology-controlled catalysts. In other words, the onset potential of the same cathode catalyst will be more positive with increasing electrolyte acidity.

Meanwhile for LSV, the reverse trend in current density: 20 $\mathrm{wt} \% \mathrm{Ag}$ cubes/C $>20 \mathrm{wt} \% \mathrm{Pt} / \mathrm{C}$ at higher over-potential may also be obtained if applying more acidic electrolytes with greater proton availability. As a result, this polarization (negative potentials) study clearly illustrates the same reversed activity trend when more negative potential is used and can also help to eliminate any potential artefacts introduced in anode and PEM components.

According to our experimental data, at more negative potential of $-2.5 \mathrm{~V}$ (rate limitation by $\mathrm{M}-\mathrm{H}$ breaking process where weaker $\mathrm{M}-\mathrm{H}$ gives higher activity), our activity ranks as $\mathrm{Ag}>$ $\mathrm{Pt}>\mathrm{Au}>\mathrm{Pd}>\mathrm{Ir}>\mathrm{Ru}$. It is interesting to compare the activity with theoretical calculations however, metal dispersion and stability under potential can sometimes be dominating factors as well. Also, there are significant discrepancies for the calculated $\mathrm{M}-\mathrm{H}$ bond strengths in literature. For example, a recent 
reference $^{39}$ (Ferrin et al.) showed the M-H bond strength $\mathrm{Ag}<$ $\mathrm{Au}<\mathrm{Pt}<\mathrm{Pd} \sim \mathrm{Ir}<\mathrm{Ru}$ (111), which contradicted Norskov's rank order of $\mathrm{Au}<\mathrm{Ir}<\mathrm{Ag}<\mathrm{Pt}<\mathrm{Pd}^{42}$ According to our own DFT calculations data (Figure S12), we have obtained that the same $\mathrm{M}-\mathrm{H}$ bond strengths as $\mathrm{Ag}<\mathrm{Au}<\mathrm{Pt}<\mathrm{Pd} \sim \mathrm{Ir}<\mathrm{Ru}$ (111) as that of Ferrin et al. Thus, our calculated M-H bond orders giving inversely relationships with their activities support our postulation as discussed in this paper (it is proposed that Au may have subjected from a degree of aggregation hence its overall activity was expected to take over Pt at further higher applied potential. Nevertheless, due to stronger $\mathrm{H}$ adsorption energy of $\mathrm{Au}$ than $\mathrm{Ag}$, the latter is anticipated to be the best catalyst at more negative applied potentials.). The discrepancies between these calculated orders between our results and others could be stemmed from the different types of facet and size of the metal cluster used.

\section{CONCLUSIONS}

In short conclusion, we have demonstrated the subtle change from low $\mathrm{H}_{2}$ production rate to an unprecedented high rate of some morphology-controlled $\mathrm{Ag} / \mathrm{C}$ particularly the $\mathrm{Ag}$ cubes due to the change of rate determining step from Volmer to Tafel, which demonstrates their higher HER activity than the commercial $\mathrm{Pt} / \mathrm{C}$ with the same metal loading in the PEM electrolyser when practically more negative potential is used. We believe that this study could rectify the misconception that $\mathrm{Pt}$ is always at the 'optimal volcano' position among all monometals in HER, which has led to an inaccurate description of the surface electrocatalysis under real PEM conditions at high workload. This work may also cast doubts on previous catalyst order in the anode under CV or LSV conditions. ${ }^{43}$ This study provides new insights into designing economical and highly efficient catalysts that can potentially replace the expensive noble metal analogues in a working electrolyser (Table S2).

\section{ASSOCIATED CONTENT}

\section{Supporting Information.}

This Supporting Information is available free of charge via the Internet at http://pubs.acs.org.

(This includes further details in synthesis, testing and characterizations such as XRD, TGA, TEM, EDX, UV-Vis, DFT, polarization curves, stability study, reaction scheme and models)

\section{AUTHOR INFORMATION}

\section{Corresponding Author}

* edman.tsang@chem.ox.ac.uk

\section{Author Contributions}

The manuscript was written through contributions of all authors. All authors have given approval to the final version of the manuscript.

\section{Funding Sources}

We acknowledge the financial support from EPSRC-IUK (EP/N510026/1) and Siemens AG for this work.

\section{ACKNOWLEDGMENT}

The TEM and SEM images provided by Hong Kong Polytechnics (Dr Weiran Zheng) are kindly acknowledged.

\section{REFERENCES}

(1) King, L. C.; Van Den Bergh, J. C. J. M. Implications of Net Energy-return-on-investment for a Low-carbon Energy Transition. Nat. Energy 2018, 3, 334-340.

(2) Dincer, I. Green Methods for Hydrogen Production. Int. J. Hydrogen Energy 2012, 37, 1954-1971.

(3) Turner, J.A. Sustainable Hydrogen Production. Science 2004, 305, 972-974

(4) Chen, Y. X.; Lavacchi, A.; Miller, H. A.; Bevilacqua, M.; Filippi, J.; Innocenti, M.; Marchionni, A.; Oberhauser, W.; Wang, L.; Vizza, F. Nanotechnology Makes Biomass Electrolysis More Energy Efficient than Water Electrolysis. Nat. Commun. 2014, 5, 1-6.

(5) Davis, S. J.; Lewis, N. S.; Shaner, M.; Aggarwal, S.; Arent D.; Azevedo, I.; Benson, S. M.; Bradley, T.; Brouwer, J.; Chiang, Y. M. Net-zero Emissions Energy Systems. Science 2018, 360, 1419.

(6) Rau, G. H.; Willauer, H. D.; Ren, Z. J. The Global Potential for Converting Renewable Electricity to Negative- $\mathrm{CO}_{2}$-emissions Hydrogen. Nat. Clim. Chang. 2018, 8, 621-625.

(7) Li, M. M. J.; Tsang, S. C. E. Bimetallic Catalysts for Green Methanol Production via $\mathrm{CO}_{2}$ and Renewable Hydrogen: A Mini-review and Prospects. Catal. Sci. Technol. 2018, 8, 3450-3464.

(8) Karunadasa, H. I.; Montalvo, E.; Sun, Y.; Majda, M.; Long, J. R.; Chang, C. J. A Molecular $\mathrm{MoS}_{2}$ Edge Site Mimic for Catalytic Hydrogen Generation. Science 2012, 335, 6090.

(9) Popczun, E. J.; McKone, J. R.; Read, C. G.; Biacchi, A. J.; Wiltrout, A. M.; Lewis, N. S.; Schaak, R. E. Nanostructured Nickel Phosphide as an Electrocatalyst for the Hydrogen Evolution Reaction. J. Am. Chem. Soc. 2013, 135, 9267-9270.

(10) Rausch, B.; Symes, M. D.; Chisholm, G.; Cronin, L. Decoupled Catalytic Hydrogen Evolution from a Molecular Metal Oxide Redox Mediator in Water Splitting. Science 2014, 345, 6202.

(11) Subbaraman, R.; Tripkovic, D.; Strmcnik, D.; Chang, K. C.; Uchimura, M.; Paulikas, A. P.; Stamenkovic, V.; Markovic, N. M. Enhancing Hydrogen Evolution Activity in Water Splitting by Tailoring $\mathrm{Li}^{+}-\mathrm{Ni}(\mathrm{OH})_{2}-\mathrm{Pt}$ Interfaces. Science 2011, 334, 6060.

(12) Ayers, K. E.; Anderson, C. B.; Capuano C. B.; Carter, B. D.; Dalton, L.T.; Hanlon, G.; Manco, J.; Niedzwiecki, M. Research Advances towards Low Cost, High Efficiency PEM Electrolysis. ECS Trans. 2010, 33(1), 3-15.

(13) Carmo, M.; Fritz, D. L.; Mergel, J.; Stolten, D. A Comprehensive Review on PEM Water Electrolysis. Int. J. Hydrogen Energy 2013, $38,4901-4934$.

(14) Suermann, M.; Schmidt, T. J.; Buchi, F. N. Investigation of Mass Transport Losses in Polymer Electrolyte Electrolysis Cells. ECS Trans. 2015, 69(17), 1141-1148.

(15) Lewinski, K. A.; Vliet, D. F.; Luopa, S. M. NSTF Advances for PEM Electrolysis - the Effect of Alloying on Activity of NSTF Electrolyzer Catalysts and Performance of NSTF Based PEM Electrolyzers . ECS Trans. 2015, 69(17), 893-971.

(16) Amin, M. A.; Fadlalah, S. A.; Alosaimi, G.S. In Situ Aqueous Synthesis of Silver Nanoparticles Supported on Titanium as Active Electrocatalyst for the Hydrogen Evolution Reaction. Int. J. Hydrogen Energy 2014, 39, 19519-19540.

(17) Tang, Q.; Wu, J.; Tang, Z.; Li, Y.; Lin, J.; Huang, M. Flexible and Macroporous Network-structured Catalysts Composed of Conducting Polymers and Pt/Ag with High Electrocatalytic Activity for Methanol Oxidation. J. Mater. Chem. 2011, 21, 13354.

(18) Gonzalez-Macia, L.; Smyth, M. R.; Killard, A. J.; Evaluation of a Silver-based Electrocatalyst for the Determination of Hydrogen Peroxide Formed via Enzymatic Oxidation. Talanta 2012, 99, 989-996. 
(19) Wen, C.; Yin, A.; Dai, W. L.; Recent Advances in Silverbased Heterogeneous Catalysts for Green Chemistry Processes. Appl. Catal., B 2014, 160-161, 730-741.

(20) Sun, Y.; Mayers, B.; Herricks, T.; Xia, Y. Polyol Synthesis of Uniform Silver Nanowires: A Plausible Growth Mechanism and the Supporting Evidence. Nano Lett. 2003, 3, 955-960.

(21) Wiley, B.; Herricks, T.; Sun, Y.; Xia, Y. Polyol Synthesis of Silver Nanoparticles: Use of Chloride and Oxygen to Promote the Formation of Single-Crystal, Truncated Cubes and Tetrahedrons. Nano Lett. 2004, 4, 1733-1739.

(22) Zeng, J.; Zheng, Y.; Rycenga, M.; Tao, J.; Li, Z.; Zhang, Q.; Zhu, Y.; Xia, Y. Controlling the Shapes of Silver Nanocrystals with Different Capping Agents. J. Am. Chem. Soc. 2010, 132, 8552-8553.

(23) Rossetti, I.; Pernicone, N.; Forni, L. Graphitised Carbon as Support for Ru/C Ammonia Synthesis Catalyst. Catal. Today 2005, 219, 102-103.

(24) Ellis, I. T.; Wolf, E. H.; Jones, G.; Lo, B.; Li, M. M. J.; York, A. P. E.; Tsang, S. C. E. Lithium and Boron as Interstitial Palladium Dopants for Catalytic Partial Hydrogenation of Acetylene. Chem. Commun. 2017, 53, 601-604.

(25) Park, I.; Lee, K.; Jung, D.; Park, H.; Sung, Y. Electrocatalytic Activity of Carbon-supported Pt-Au Nanoparticles for Methanol Electro-oxidation. Eletrochimica. Acta. 2007, 52, 5599-5605.

(26) Brightman, E.; Dodwell, J.; Dijk, N. V.; Hinds, G. In Situ Characterisation of PEM Water Electrolysers Using a Novel Reference Electrode. Electrochem. Commun. 2015, 52, 1-4.

(27) Kresse, G.; Furthmüller, J. Efficient Iterative Schemes for Ab initio Total-energy Calculations Using a Plane-wave Basis Set. Phys. Rev. B. 1996, 54, 11169-11186.

(28) Perdew, J. P.; Chevary, J.A.; Vosko, S. H.; Jackson, K.A.; Pederson, M.R.; Singh, D.J.; Fiolhais, C. Erratum: Atoms, Molecules, Solids, and Surfaces: Applications of the Generalized Gradient Approximation for Exchange and Correlation. Phys. Rev. B 1993, 48, 49784978.

(29) White, J. A.; Bird, D. M. Implementation of Gradient-corrected Exchange-correlation Potentials in Car-Parrinello Total-energy Calculations. Phys. Rev. B 1994, 50, 4954-4957.

(30) Dang, S. S.; Jacob, T.; Hansen, T. W.; Wang, D.; Schlogl, R.; Freitag, B.; Kujawa, S. Surface Chemistry of Ag Particles: Identification of Oxide Species by Aberration - Corrected TEM and by DFT Calculations. Angew. Chem., Int. Ed. 2008, 47, 5005-5008.

(31) Yu, D.; Yam, V. W. Controlled Synthesis of Monodisperse Silver Nanocubes in Water. J. Am. Chem. Soc. 2004, 55, 13200-13201.
(32) Sun, Y.; Xia, Y. Shape-Controlled Synthesis of Gold and Silver Nanoparticles. Science 2002, 298, 2176-2179.

(33) Sun, Y.; Gates, B.; Mayers, B.; Xia, Y. Crystalline Silver Nanowires by Soft Solution Processing. Nano Lett. 2002, 2, 165-168.

(34) Wiley, B.; Sun, Y.; Chen J.; Cang, H.; Li, Z.; Li, X.; Xia, Y. Shape-Controlled Synthesis of Silver and Gold Nanostructures. Bulletin 2005, 30, 356-361.

(35) Skúlason, E.; Tripkovic, V.; Bjorketun, M. E.; Gudmundsdottir, S.; Karlberg, G.; Rossmeist, J.; Bligaard, T.; Jonsson, H.; Norskov, J.K. Modeling the Electrochemical Hydrogen Oxidation and Evolution Reactions on the Basis of Density Functional Theory Calculations. J. Phys. Chem. C 2010, 114, 18182-18197.

(36) Nørskov, J. K.; Bligaard, T.; Rossmeisl, J.; Christensen, C. H. Towards the Computational Design of Solid Catalysts. Nat. Chem. 2009, 1, 37-46.

(37) Durst, J.; Simon, C.; Hasche, F.; Gasteiger, H. A. Hydrogen Oxidation and Evolution Reaction Kinetics on Carbon Supported Pt, Ir, Rh, and Pd Electrocatalysts in Acidic Media. J. Electrochem. Soc. 2015, 162, F190-F203.

(38) Shinagawa, T.; Garcia-Esparza, A. T.; Takanabe, K. Insight on Tafel Slopes from a Microkinetic Analysis of Aqueous Electrocatalysis for Energy Conversion. Sci. Rep. 2015, 5, 13801.

(39) Ferrin, P.; Kandoi, S.; Nilekar, A. U.; Mavrikakis, M. Hydrogen Adsorption, Absorption and Diffusion on and in Transition Metal Surfaces: A DFT Study. Surf. Sci. 2012, 606, 679-689.

(40) Liu, L.; Chen, W.; Li, Y. J. An Overview of the Proton Conductivity of Nafion Membranes through a Statistical Analysis. Memb. Sci. 2016, 504, 1-9.

(41) Conway, B. E.; Tilak, B. V. Interfacial Processes Involving Electrocatalytic Evolution and Oxidation of $\mathrm{H}_{2}$, and the Role of Chemisorbed H. Electrochimica Acta 2002, 47, 3571-3594.

(42) Norskov, J. K.; Bligaard, T.; Logadottir, A.; Kitchin, J. R.; Chen, J. G.; Pandelov, S.; Stimming, U. Trends in the Exchange Current for Hydrogen Evolution. J. Electrochem. Soc. 2005, 152, J23-J26.

(43) Seh, Z. W.; Kibsgaard, J.; Dickens, C. F.; Chorkendorff, I.; Norskov, J. K.; Jaramillo, T. F. Combining Theory and Experiment in Electrocatalysis: Insights into Materials Design. Science 2017, 355, 6321. 
TOC

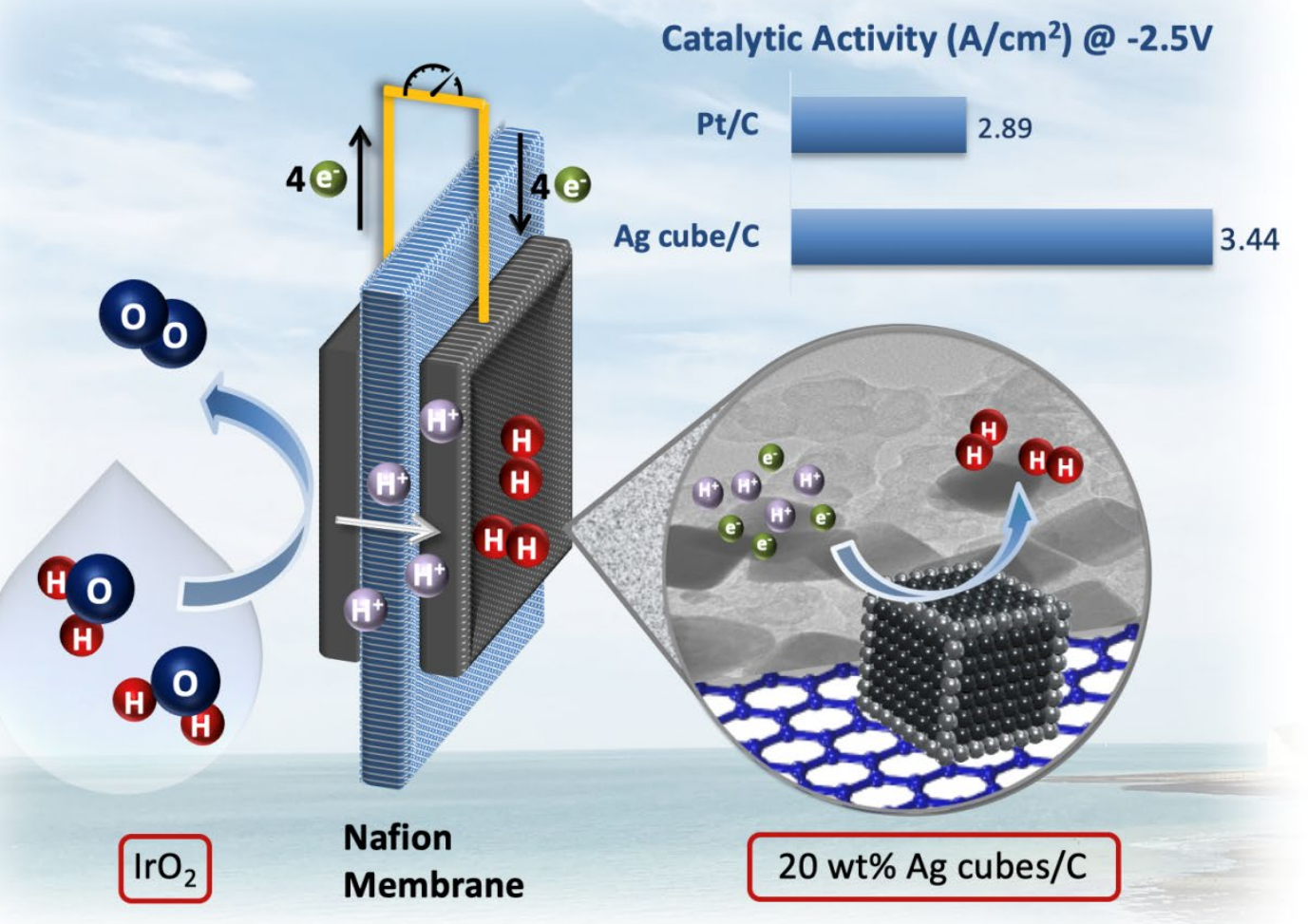

